\title{
Aerosolized Chemotherapy
}

\author{
FREDERIC GAGNADOUX, M.D., Ph.D., ${ }^{1}$ JOSE HUREAUX, M.D., ${ }^{1}$ \\ LAURENT VECELLIO, Ph.D., ${ }^{2}$ THIERRY URBAN, M.D., Ph.D., ${ }^{2}$ ALAIN LE PAPE, Ph.D., ${ }^{2,3}$ \\ ISABELLE VALO, M.D., ${ }^{4}$ JEROME MONTHARU, ${ }^{2}$ VALERIE LEBLOND, Ph.D., ${ }^{2}$ \\ MICHELE BOISDRON-CELLE, Ph.D., 5 STEPHANIE LERONDEL, Ph.D., 3,6 \\ CAROLINE MAJORAL, Ph.D., ${ }^{2}$ PATRICE DIOT, M.D., Ph.D., ${ }^{2}$ JEAN L. RACINEUX, M.D., ${ }^{1}$ \\ and ETIENNE LEMARIE, M.D. ${ }^{2}$
}

\begin{abstract}
Regional chemotherapy has been proposed as a treatment modality in a number of cancer settings. In primary or metastatic lung cancer, administration of chemotherapy via inhalation could increase exposure of lung tumor to the drug, while minimizing systemic side effects. Several proof of concept studies in animal models of metastatic or primary lung cancer have demonstrated the safety, pharmacokinetic advantage, and antitumor effect of aerosol administration of several chemotherapeutic agents including doxorubicin, gemcitabine and liposome-encapsulated formulations of paclitaxel and 9-nitrocamptothecin (9-NC). Recent phase I studies have demonstrated the feasibility of aerosol delivery of doxorubicin and liposomal formulations of 9-NC and cisplatin in patients with primary and metastatic lung cancer with a limited pharmacokinetic profile consistent with the observed low systemic toxicity. Further studies integrating safety, pharmacokinetic, and efficacy considerations are required to determine whether there is a place for local administration of chemotherapy via inhalation in lung cancer.
\end{abstract}

Key words: lung cancer, chemotherapy, regional, aerosol

\section{INTRODUCTION}

L UNGS ARE A COMMON SITE for both primary and secondary tumors. In the United States, 170,000 new cases of primary lung cancer and 65,000 new cases of metastatic lung cancer are diagnosed each year. Nonsmall-cell lung cancer (NSCLC) is diagnosed in $80 \%$ of primary tu- mors. ${ }^{(1)}$ Metastatic lung cancer is frequently detected in patients with lung, breast, colorectal, pancreas, gastric, kidney, and head and neck carcinomas, and melanoma. ${ }^{(2-4)}$ Lung carcinoma is the leading cause of cancer-related death worldwide. $^{(1)}$ Only a minority of patients with primary lung cancer are eligible for curative surgical resection. Similarly, surgical treatment of lung

\footnotetext{
${ }^{1}$ Département de Pneumologie, CHU, Angers, France.

${ }^{2}$ INSERM, U618, IFR135, Faculté de Médecine, Tours, France.

${ }^{3}$ CDTA-CNRS, Orléans, France.

${ }^{4}$ Laboratoire d(anatomopathologie, CRLCC Paul Papin, Angers, France.

${ }^{5}$ Laboratoire d'Oncopharmacologie-Pharmacogénétique, INSERM U564, CRLCC Paul Papin, Angers, France.

${ }^{6}$ Biopharmconsulting, ARAIR, Tours, France.
} 
metastasis is often contraindicated due to the number or the site of the lesions and the patient's respiratory and/or general status. Chemotherapy is therefore widely used in both primary and secondary lung carcinomas. Despite the use of new chemotherapeutic agents during the last decade, the ceiling of their clinical efficacy remains low with a 5-year survival rate of metastatic NSCLC that levels off at $5-15 \% .{ }^{(5)}$ Studies have demonstrated that drug concentrations in lung tumors are low after systemic administration that could be a cause of treatment failure, ${ }^{(6)}$ as the drug concentration in the tumor appears to be a key parameter to achieve drug efficacy in humans. ${ }^{(7)}$ These data support the potential value of targeted chemotherapy to lung tumors, as already successfully applied in several cancer settings such as liver metastasis, ovarian tumors, neoplastic meningitis or brain tumors. ${ }^{(8-11)}$

\section{RATIONALE AND POTENTIAL LIMITATIONS OF AEROSOLIZED CHEMOTHERAPY IN LUNG CANCER}

Direct drug administration to the lungs via inhalation offers several theoretical advantages over systemic delivery, including the possibility of regional drug delivery to the lungs and airways with lower doses and fewer systemic side effects, avoiding first-pass metabolism of the drug in the liver and the use of a noninvasive "needle-free" delivery system. ${ }^{(12)}$ The alveolar surface also provides a large surface area for rapid systemic absorption of soluble drugs. The most common application of aerosol therapy is regional drug delivery for airway and parenchymal lung diseases, but there is also an expanding role of aerosols in systemic drug delivery such as insulin for diabetes. ${ }^{(13)}$ Local delivery of chemotherapy via inhalation for primary or metastatic lung cancer could increase drug exposure of the lung tumor, while minimizing systemic side effects.

Although use of aerosolized chemotherapy was first reported in 1968,(14) the development of inhalational agents for oncologic use has been limited. ${ }^{(6)}$ A potential explanation is the fear of pulmonary toxicity. Several chemotherapeutic agents, including novel compounds such as irinotecan, gemcitabine, paclitaxel, and docetaxel, can cause severe pulmonary reactions that develop during, or shortly after, treatment. $(15,16)$

Local administration of high doses of chemotherapy via inhalation may increase the risk of drug-induced lung disease. Furthermore, a high proportion of patients with lung cancer have impaired pulmonary function due to tobacco-related illness ${ }^{(17)}$ that could worsen the prognosis in the case of chemotherapy-induced lung disease. The risk of direct toxicity to the lungs must therefore be evaluated for each new drug considered for aerosol administration.

Another safety issue is occupational exposure of healthcare workers to the nebulized drug. Aerosolized chemotherapy must be delivered in a well-ventilated room with an air filtering system. A recent study demonstrated the effectiveness of a mobile HEPA filter air cleaning system combined with a demistifier tent to prevent propagation of aerosol during inhalation of nebulized liposomal cisplatin. ${ }^{(18)}$

In order to be effective, aerosolized chemotherapy must be delivered at a sufficient concentration to the target area. Aerosol particle size is one of the most important determinants of aerosol dose and distribution in the lungs. ${ }^{(12)}$ Aerosols with a mass median aerodynamic diameter (MMAD) of 5-10 $\mu \mathrm{m}$ are mainly deposited in the oropharynx and large conducting airways. Particles of 1-5 $\mu \mathrm{m}$ diameter are deposited in the small airways, and alveoli with $>50 \%$ of $3 \mu \mathrm{m}$-diameter particles being deposited in the alveolar region. The optimal site of deposition for aerosolized chemotherapy may be different for primary lung cancer located in or near the central airways, for bronchioloalveolar carcinoma located in the alveolar region and for multiple parenchymal metastases. Aerosol deposition in the target area can also be altered in the case of airway obstruction by the tumor or associated obstructive lung disease. ${ }^{(19)}$

The inhaled drug may reach the tumor either via direct topical penetration for bronchogenic carcinomas located close to the airways or via the local blood supply (bronchial or pulmonary circulation) for smaller primary or metastatic lung tumors located away from the airways. ${ }^{(6)}$

Finally, little is known about the pulmonary metabolism of inhaled drugs, ${ }^{(20)}$ which may influence the therapeutic efficacy and pharmacokinetics of an aerosolized chemotherapeutic agent. 


\section{PROOF OF CONCEPT STUDIES}

\section{Pharmacokinetic advantage of inhaled chemotherapy}

Isotopic studies have been performed to compare pulmonary deposition of ${ }^{14} \mathrm{C}$-labeled doxorubicin in dogs after aerosol and i.v. administration at the same dosage. ${ }^{(6)}$ Compared with the i.v. route, aerosol administration of ${ }^{14} \mathrm{C}$-labeled doxorubicin was associated with a marked increase in the level of radioactivity in the lungs with very low systemic concentrations of the drug after inhalation. Koshkina et al. ${ }^{(21)}$ compared the pulmonary pharmacokinetics of a liposomal formulation of paclitaxel after aerosol and i.v. administration at comparative doses in mice. The deposition and clearance of the drug in the lung tissue extracts were determined using high-performance liquid chromatography. The authors found higher concentrations and slower clearance of paclitaxel from the lungs after aerosol delivery. The area under the curve in the lungs was 26-fold higher after aerosol delivery than after i.v. injection.

\section{Safety and antitumor effect of aerosolized chemotherapy}

The cytotoxic effect of chemotherapeutic agents after nebulization has been studied in vitro using growth inhibition assays. Wang et al. ${ }^{(22)}$ assessed the cytotoxic properties of farnesol nebulized by two different nebulizers [Pari LC Star and LC Plus (vented, valved jet nebulizers) driven by a Proneb Ultra compressor (Pari, Starnberg, Germany)] in two NSCLC cell lines (NCI$\mathrm{H} 460$ et A549). This study demonstrated that cytotoxic properties in vitro of farnesol are not altered by nebulization.

Gemcitabine (GCB) is a chemotherapeutic agent belonging to the nucleoside analog family. It has been demonstrated to be effective in the treatment of NSCLC, ${ }^{(23)}$ both as monotherapy and in combination with other drugs. It is a prodrug, which is inactive in the extracellular compartment. It becomes cytotoxic once it enters into a nucleated cell, in which it undergoes several phosphorylations. ${ }^{(24)}$ The GCB formulation does not contain any chemical compound incompatible with aerosol delivery.

These advantages, combined with solubility in saline and the absence of irritant effects, make
GCB an attractive candidate for local administration. Similar cytotoxic properties have been observed with nebulized and nonnebulized GCB against NCI-H460 and A549 NSCLC cells(25) (Fig. 1 ). The concentration of nebulized GCB causing $50 \%$ growth inhibition was similar to that previously observed with nonnebulized GCB. ${ }^{(26)}$

Several proof of concept studies of aerosolized chemotherapy have been performed in animal models of metastatic lung cancer. ${ }^{(21,27,28)}$ In these studies, animals were exposed to the aerosol generated by a jet nebulizer in a sealed plastic box. The amount of drug deposited in the lungs was estimated by taking into account the concentration of drug in aerosol volume, the volume of air inspired by the animal in $1 \mathrm{~min}$, the estimated deposition index, and the duration of treatment (30 to $120 \mathrm{~min}$ ). Using this procedure, the efficacy of aerosolized chemotherapy with liposome-encapsulated 9-nitrocamptothecin (L-9NC) was evaluated in two different experimental lung metastasis models. ${ }^{(27)}$

In C57BL/ 6 mice, L-9NC aerosols were started the day after i.v. injection of B16 melanoma cells and were delivered for $1 \mathrm{~h}, 5$ days a week for up to 3 weeks. A preventive effect of aerosolized L$9 \mathrm{NC}$ was observed with fewer lung metastases in treated mice than in control mice.

In a second model, aerosols were started on the ninth week after osteosarcoma cells i.v. injection in nude mice. A curative effect of aerosolized L9NC was observed against established lung metastases. The murine RENCA model, based on i.v. injection of renal carcinoma cells, offers the potential advantage of a lack of early disease symptoms leading to the formation of distant metastasis, including the lungs.

The antitumor effect of a liposomal formulation of paclitaxel delivered to the lungs by aerosol was studied in the RENCA model.(21) Aerosols were initiated the day after renal carcinoma cell inoculation and were delivered for 2 weeks. A control group of mice received aerosols of blank liposomes. The study demonstrated a preventive effect of liposomal paclitaxel aerosols delivered 3 days per week with a reduced number of visible lung metastases and prolonged survival compared to control groups.

A recent study from the same group evaluated the antitumor effect of aerosolized GCB compared to aerosolized saline in two models of osteosarcoma lung metastasis. ${ }^{(28)}$ Treatments were 
a
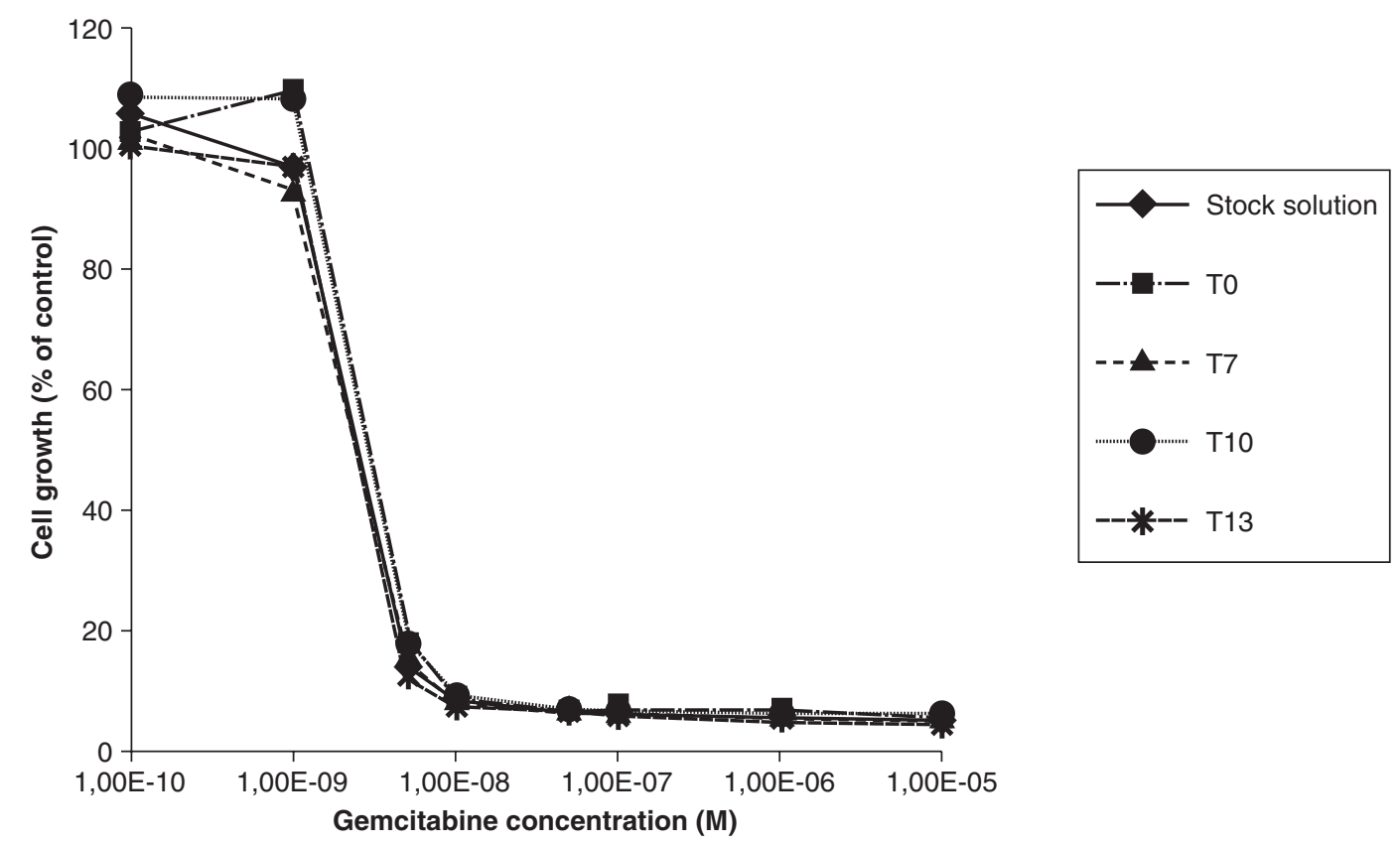

b
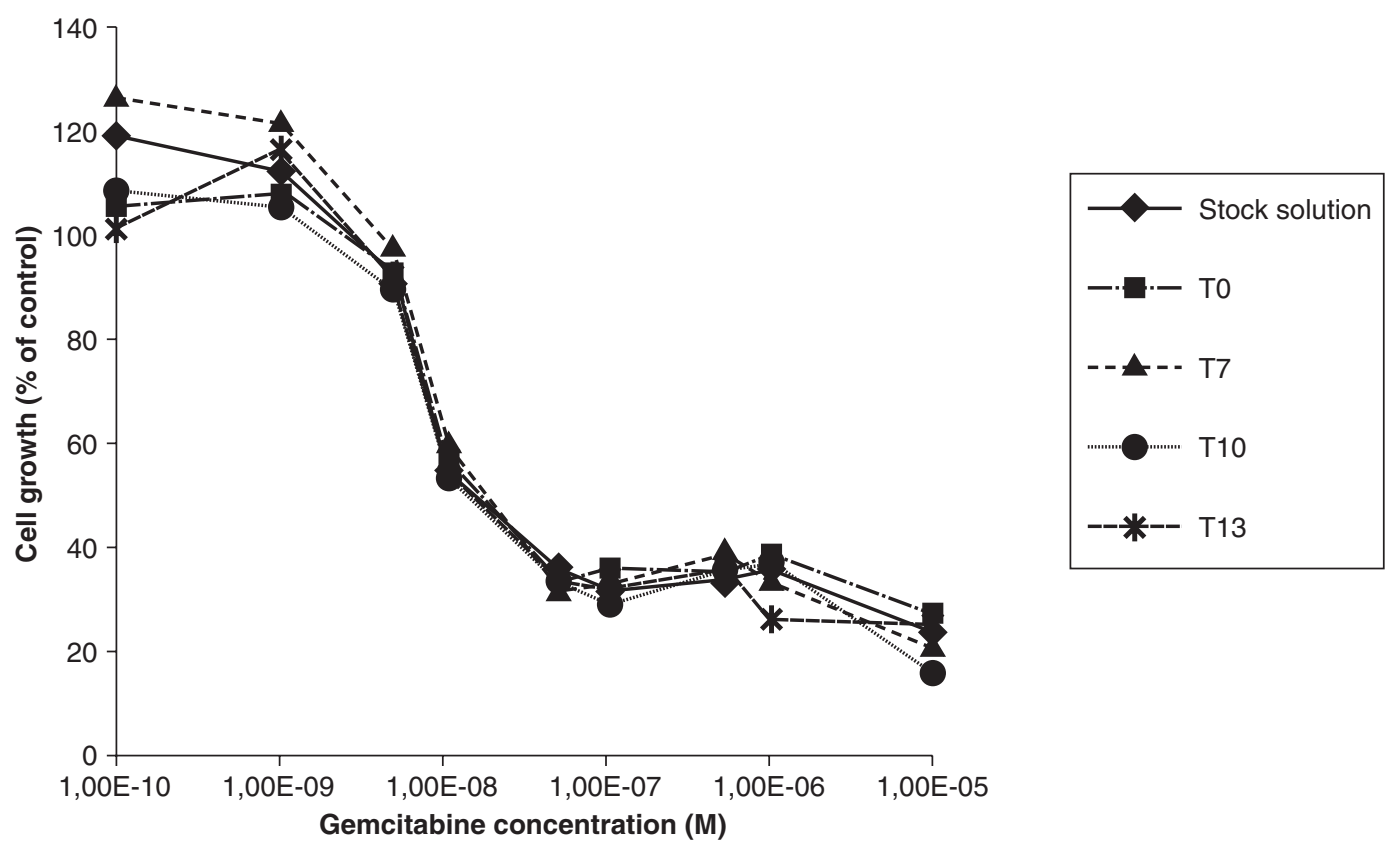

FIG. 1. Growth inhibition assay of nonnebulized and nebulized gemcitabine on NCI-H460 (a) and A549 (b) nonsmall-cell lung cancer cells; T0: gemcitabine before nebulization; T7, T10, and T13: gemcitabine after 7, 10, and 13 minutes of nebulization (see ref. 26)

initiated 4 weeks after tumor cell inoculation when the presence of lung metastasis had been established. In the LM7 osteosarcoma lung metastasis model, the best therapeutic response was observed in mice treated with $1 \mathrm{mg} / \mathrm{kg}$ of GCB aerosol twice a week. No visible lung metastasis was observed 10.5 weeks after i.v. injection of human LM7 cells. After i.v. injection, LM8 osteosarcoma cells grow subcutaneously then spontaneously metastasize to the lungs. In this model, GCB aerosol at a dose of $0.5 \mathrm{mg} / \mathrm{kg}$ three times weekly was compared to the same regimen via 
the i.p. route. Inhibition of lung metastasis was observed only in the GCB aerosol group compared to aerosolized saline. GCB administered by i.p. injection had no impact on the number of lung metastases. Interestingly, a systemic effect of aerosolized GCB was observed with an inhibitory effect on subcutaneous tumor growth similar to that observed in the animals treated with i.p. GCB.

The antitumor effect of aerosolized GCB has also been studied in an orthotopic model of large cell undifferentiated primary lung cancer based on intrabronchial implantation of NCI-H460 cancer cells in BALB/c nude mice. ${ }^{(29)}$ The histologic characteristics of orthotopic tumor models have been demonstrated to be consistent with the clinical tumor from which the cell lines are derived. Furthermore, when cells are implanted intrabronchially, tumors predominantly grow in the lung parenchyma. ${ }^{(30)}$ Weekly GCB aerosols were initiated the day after cell implantation for up to 9 weeks, using an endotracheal sprayer with scintigraphic assessment of pulmonary deposition as a model of aerosol delivery in rodents. ${ }^{(31)}$ Compared to control mice treated with aerosolized saline, weekly GCB aerosols were associated with complete inhibition of tumor growth in $31 \%$ cases and partial inhibition of tumor growth in the remaining cases. A dose effect of aerosolized GCB on tumor growth was observed (Fig. 2). At the dosage of $8 \mathrm{mg} / \mathrm{kg} /$ week,

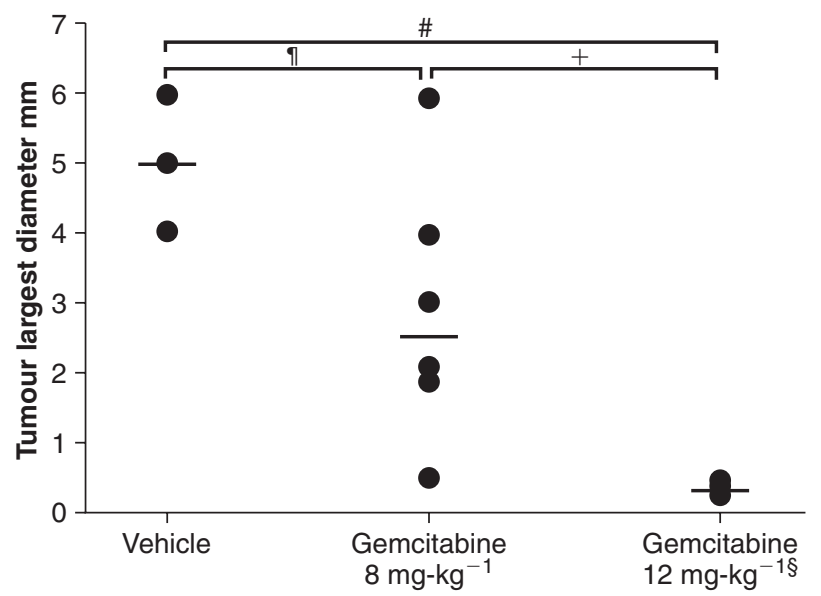

FIG. 2. Median and individual values of largest tumor diameter in the animals treated with 9 weekly administrations of vehicle or GCB aerosol. ${ }^{\#} p=0.014$; ${ }^{\mathbb{I}} p=0.042$; ${ }^{+} p=0.02$; \$animals received $12 \mathrm{mg} \cdot \mathrm{kg}^{-1}$ of gemcitabine on day (d) 1 and $\mathrm{d} 8$ followed by $8 \mathrm{mg} \cdot \mathrm{kg}^{-1}$ on $\mathrm{d} 15, \mathrm{~d} 22$, and $\mathrm{d} 29$ (see ref. 30). aerosolized GCB was well tolerated, with no clinical and histologic signs of toxicity.

In a previous study Hershey et al. ${ }^{(32)}$ treated 24 anesthetized dogs with advanced stages of spontaneous primary lung cancer or lung metastases with paclitaxel or doxorubicin aerosols administered twice weekly. Tumor regression was achieved in $25 \%$ of dogs with measurable tumors without the systemic side effects normally associated with i.v. administration of these drugs and without pulmonary toxicity in the dogs treated with paclitaxel. Changes consistent with pneumonitis/fibrosis were observed in some dogs treated with doxorubicin aerosols.

\section{CLINICAL STUDIES}

One of the first reports of aerosolized chemotherapy in lung cancer was published by Tatsamura et al. in 1993. ${ }^{(33)}$ In this pilot study, 5-fluorouracil (5-FU) $(250 \mathrm{mg}$ in $5 \mathrm{~mL}$ ) was delivered via inhalation using an ultrasonic nebulizer in patients with NSCLC in two situations.

In the first part of the study, pulmonary deposition of aerosolized 5-FU was documented in 19 patients with resectable NSCLC who received one aerosol $2 \mathrm{~h}$ before thoracic surgery. The authors demonstrated that aerosolized 5-FU accumulated at therapeutic concentrations in the trachea, bronchi, and regional lymph nodes along with 5-FU metabolites, FUR and FUdR, indicating that the drug was directly incorporated and metabolized in the respiratory tract. Only a trace of 5-FU was found in the serum. Interestingly, 5FU concentrations were 5- to 15-fold higher in the tumor than in normal lung tissue.

In the second part of the study, 10 selected patients with unresectable NSCLC were treated by daily 5-FU aerosols two to three times a week. None of the included patients had been previously treated. Six objective responses were observed, including four partial responses and two complete responses without stomatitis or any other significant pulmonary or systemic side effects.

Three phase I studies of aerosolized chemotherapy including dose escalation and pharmacokinetics have been performed in patients with primary or metastatic lung cancer who did not respond to previous conventional treatment. ${ }^{(34-36)}$ On the basis of previous successful experiments in animal models, $(27,37,38)$ a clinical 
evaluation of aerosolized L-9NC was performed in 25 patients, including 6 patients with primary lung cancer. ${ }^{(34)}$ Aerosols were delivered 5 days/week via a mouth breathing-only face mask using a jet nebulizer in a HEPA-filtered airborne scavenging tent. Interestingly, patients were allowed to self-administer treatment at home with a portable air compressor and a HEPA-filtering system if no side effect greater than grade 2 was observed. The dose-limiting toxicity (DLT) of aerosolized L-9NC was chemical pharyngitis. Grade 2 toxicity included nausea/vomiting, cough, and bronchial irritation and fatigue. A reversible $20 \%$ decrease of $\mathrm{FEV}_{1}$ was observed. There was no haematological toxicity. In five patients, bronchoscopy with bronchoalveolar lavage (BAL) at the end of treatment revealed 9NC concentrations 4- to 10-fold higher in BAL fluid than in plasma. Partial remissions were observed in two patients with uterine cancer, and stabilization occurred in three patients with primary lung cancer. A partial remission of a liver metastasis was also observed, confirming the systemic potential of aerosolized L-9NC previously observed in animal models. ${ }^{(37)}$

This study was the basis for the recommended dosage for two ongoing phase II trials of aerosolized L-9NC: one in primary lung cancer, and one in metastatic endometrial cancer (ClinicalTrials.gov). Two phase I studies were published in 2007. ${ }^{(35,36)}$

Otterson et al. ${ }^{(35)}$ studied the toxicity profile of doxorubicin aerosolized every 3 weeks, using a Pari LC Plus nebulizer housed within a sealed containment system with a mouth-only inhalation apparatus, in 53 patients with metastatic lung disease. This study was marked by a pulmonary DLT with five severe (grade 3-4) pulmonary adverse events including one case of grade 4 respiratory distress, grade 3 hypoxia, $>20 \%$ drop in forced vital capacity, and ground glass opacities. Conversely, the limited pharmacokinetic profile was consistent with the observed minimal systemic toxicity. One partial response was documented in a patient with metastatic sarcoma and eight patients had disease lasting $\geq 5$ courses. Finally, the safety and pharmacokinetics of aerosolized cisplatin encapsulated in lipid vesicles (sustained release lipid inhalation targeting $=$ SLIT) was recently investigated in $17 \mathrm{pa}-$ tients with histologically proven lung cancer (16 NSCLC). ${ }^{(36)}$ Aerosols were delivered 1 to 4 consecutive days in 21-day treatment cycles. The number of daily inhalation sessions in combination with the number of treatment days was considered to be the limiting factor and no DLT was achieved at the maximum delivered dose. Apart from nausea and vomiting, the most commonly observed adverse events concerned the respiratory tract (including a grade $1-2$ decrease in $\mathrm{FEV}_{1}$ and DLCO), but the usual systemic toxicity of cisplatin (hematologic toxicity, nephrotoxicity, ototoxicity) was not observed. The SLIT cisplatin aerosol produced by the Pari LC Star nebulizer had a mass median aerodynamic diameter (MMAD) of $3.7 \mu \mathrm{m}$ and a geometric SD of $1.9 \mu \mathrm{m}$. Pharmacokinetic data showed very low plasma platinum levels. Best overall response observed in this study was stable disease in 12 patients.

On the basis of successful preclinical experiments on weekly aerosol delivery of GCB in animal models, $(25,29,31)$ a phase I study is ongoing in patients with NSCLC. ${ }^{(39)}$ Weekly GCB aerosols are delivered via a chamber (Idehaler ${ }^{\mathrm{TM}}$, Atomisor, France) operated with a mesh nebulizer (Aeroneb $^{\mathrm{TM}}$, Pro, Aerogen, Mountain View, CA) $(\mathrm{MMAD}=5 \mu \mathrm{m})^{(40)}$ in a specially designed closed cabin equipped with an air extraction and filtering system. ${ }^{(25)}$ Scintigraphic assessment of the delivered dose is performed at the first inhalation using ${ }^{99 \mathrm{~m} T c-D T P A}(5 \mathrm{mCi})$ as tracer of the aerosol. ${ }^{(25)}$ Preliminary results in six patients demonstrate the feasibility of 9 weekly aerosols of 0.5 and $1 \mathrm{mg} / \mathrm{kg}$ of GCB.

\section{CONCLUSIONS AND PERSPECTIVES}

Preclinical studies in animal models have demonstrated the safety, pharmacokinetic advantage, and antitumor effect of aerosol administration of several chemotherapeutic agents including doxorubicin, gemcitabine, and liposomeencapsulated formulations of paclitaxel and 9NC. $(21,27,29,41)$

Recent phase I studies demonstrated the feasibility of aerosol delivery of doxorubicin and liposomal formulations of 9-NC and cisplatin in patients with primary and metastatic lung cancer with a limited pharmacokinetic profile consistent with the observed low systemic toxicity. ${ }^{(34-36)}$ Most adverse events of aerosolized chemotherapy were due to direct effects of the inhaled drug on the upper and lower respiratory tract including pulmonary dose-limiting toxicity for doxorubicin. ${ }^{(35)}$ Although the advanced stage of the dis- 
ease in patients included in phase I studies makes it difficult to draw any conclusions regarding the efficacy of aerosolized chemotherapy, some responses were observed including partial remission of liver metastasis in the L-9NC study demonstrating a potential systemic effect of the inhaled drug. ${ }^{(34)}$

Further studies integrating safety, pharmacokinetic, and efficacy considerations are required to determine whether there is room for local administration of chemotherapy via inhalation in lung cancer. For each new drug considered for aerosol delivery, preclinical studies including a deposition study are required for safety assessment. Sustained release from a therapeutic aerosol can prolong the residence of an inhaled drug in the airways or alveolar space increasing local efficacy and reducing dosing frequency. ${ }^{(20)}$ Liposomes can be used to encapsulate a variety of drugs with a wide range of lipophilicities. The lipid nature of the sphere can promote mononuclear phagocyte uptake and absorption into lymphatic vessels commonly involved by tumor metastasis. ${ }^{(36)}$ A study of 5-FU in lipid-coated nanoparticles administered by inhalation to hamsters demonstrated targeted drug-delivery and sustained effective 5-FU concentrations in the lungs. ${ }^{(42)}$

Several strategies could be considered for the use of aerosolized chemotherapy in thoracic oncology. In primary lung cancer, regional chemotherapy via inhalation could be useful in selected situations. Bronchioloalveolar carcinoma, a rare form of NSCLC composed of alveolar epithelial tumor cells filling up the alveolar space and gradually inducing respiratory insufficiency or evolving into invasive adenocarcinoma, ${ }^{(43)}$ could constitute a potential indication for aerosolized chemotherapy. Regional drug delivery via the airways could allow direct exposure of cancer cells to the therapeutic agent. Aerosolized chemotherapy could also be useful in unresectable main bronchus carcinoma with limited invasion or tumor relapse after surgery. Inhaled chemotherapy could be considered as adjuvant therapy in combination with other treatment modalities such as surgery or systemic chemotherapy in advanced disease. Aerosol therapy could have potential applications for local administration of chemopreventive agents. ${ }^{(44)}$ In a hamster model, aerosol delivery of 5-FU was demonstrated to reduce the occurrence of infiltrating squamous cell carcinoma of the upper respiratory tract induced by local instillation of methylni- trosourea. ${ }^{(45)}$ Several nonchemotherapeutic agents may also take advantage of local delivery through the respiratory tract, such as activators of the local immune system, ${ }^{(46,47)}$ gene therapy, ${ }^{(48)}$ and COX-2 inhibitors. ${ }^{(49,50)}$

\section{ACKNOWLEDGMENTS}

None of the authors declare any conflicts of interest.

\section{REFERENCES}

1. Jemal A, Murray T, Samuels A, Ghafoor A, Ward E, and Thun MJ: Cancer statistics, 2003. CA Cancer J Clin. 2003;53:5-26.

2. Johnson RM, and Lindskog GE: 100 cases of tumor metastatic to lung and mediastinum. Treatment and results. JAMA. 1967;202:94-98.

3. Putnam JB Jr, and Roth JA: Prognostic indicators in patients with pulmonary metastases. Semin Surg Oncol. 1990;6:291-296.

4. Woodard PK, Dehdashti F, and Putman CE: Radiologic diagnosis of extrathoracic metastases to the lung. Oncology. 1998;12:431-438; discussion 441-444.

5. Schiller JH, Harrington D, Belani CP, Langer C, Sandler A, Krook J, Zhu J, and Johnson DH: Comparison of four chemotherapy regimens for advanced nonsmall-cell lung cancer. N Engl J Med. 2002;346:92-98.

6. Sharma S, White D, Imondi AR, Placke ME, Vail DM, and Kris MG: Development of inhalational agents for oncologic use. J Clin Oncol. 2001;19:1839-1847.

7. Minchinton AI, and Tannock IF: Drug penetration in solid tumours. Nat Rev Cancer. 2006;6:583-592.

8. Kemeny NE, Niedzwiecki D, Hollis DR, Lenz HJ, Warren RS, Naughton MJ, Weeks JC, Sigurdson ER, Herndon JE 2nd, Zhang C, and Mayer RJ: Hepatic arterial infusion versus systemic therapy for hepatic metastases from colorectal cancer: a randomized trial of efficacy, quality of life, and molecular markers (CALGB 9481). J Clin Oncol. 2006;24:1395-1403.

9. Armstrong DK, Bundy B, Wenzel L, Huang HQ, Baergen R, Lele S, Copeland LJ, Walker JL, and Burger RA: Intraperitoneal cisplatin and paclitaxel in ovarian cancer. N Engl J Med. 2006;354:34-43.

10. Guerin C, Olivi A, Weingart JD, Lawson HC, and Brem H: Recent advances in brain tumor therapy: local intracerebral drug delivery by polymers. Invest New Drugs. 2004;22:27-37.

11. Glantz MJ, Jaeckle KA, Chamberlain MC, Phuphanich S, Recht L, Swinnen LJ, Maria B, LaFollette S, Schumann GB, Cole BF, and Howell SB: A randomized controlled trial comparing intrathecal sustained-release cytarabine (DepoCyt) to intrathecal methotrexate in patients with neoplastic meningitis from solid tumors. Clin Cancer Res. 1999;5:3394-3402. 
12. Labiris NR, and Dolovich MB: Pulmonary drug delivery. Part I: physiological factors affecting therapeutic effectiveness of aerosolized medications. Br J Clin Pharmacol. 2003;56:588-599.

13. Laube BL: The expanding role of aerosols in systemic drug delivery, gene therapy, and vaccination. Respir Care. 2005;50:1161-1176.

14. Shevchenko IT, and Resnik GE. Inhalation of chemical substances and oxygen in radiotherapy of bronchial cancer. Neoplasma. 1968;15:419-426.

15. Camus P, Fanton A, Bonniaud P, Camus C, and Foucher P: Interstitial lung disease induced by drugs and radiation. Respiration. 2004;71:301-326.

16. Camus P: Interstitial lung disease in patients with non-small-cell lung cancer: causes, mechanisms and management. Br J Cancer. 2004;91(Suppl 2):S1-S2.

17. Sarna L, Padilla G, Holmes C, Tashkin D, Brecht ML, and Evangelista L: Quality of life of long-term survivors of non-small-cell lung cancer. J Clin Oncol. 2002;20:2920-2929.

18. Wittgen BP, Kunst PW, Perkins WR, Lee JK, and Postmus PE: Assessing a system to capture stray aerosol during inhalation of nebulized liposomal cisplatin. J Aerosol Med. 2006;19:385-391.

19. Itoh H, Ishii $Y$, Maeda H, Todo G, Torizuka K, and Smaldone GC: Clinical observations of aerosol deposition in patients with airways obstruction. Chest. 1981;80(Suppl):837-840.

20. Labiris NR, and Dolovich MB: Pulmonary drug delivery. Part II: the role of inhalant delivery devices and drug formulations in therapeutic effectiveness of aerosolized medications. Br J Clin Pharmacol. 2003;56: 600-612.

21. Koshkina NV, Waldrep JC, Roberts LE, Golunski E, Melton S, and Knight V: Paclitaxel liposome aerosol treatment induces inhibition of pulmonary metastases in murine renal carcinoma model. Clin Cancer Res. 2001;7:3258-3262.

22. Wang Z, Chen HT, Roa W, and Finlay W. Farnesol for aerosol inhalation: nebulization and activity against human lung cancer cells. J Pharm Pharm Sci. 2003;6:95-100.

23. Perng RP, Chen YM, Ming-Liu J, Tsai CM, Lin WC, Yang KY, and Whang-Peng J: Gemcitabine versus the combination of cisplatin and etoposide in patients with inoperable non-small-cell lung cancer in a phase II randomized study. J Clin Oncol. 1997;15: 2097-2102.

24. Mackey JR, Mani RS, Selner M, Mowles D, Young JD, Belt JA, Crawford CR, and Cass CE: Functional nucleoside transporters are required for gemcitabine influx and manifestation of toxicity in cancer cell lines. Cancer Res. 1998;58:4349-4357.

25. Gagnadoux F, Leblond V, Vecellio L, Hureaux J, Le Pape A, Boisdron-Celle M, Montharu J, Majoral C, Fournier J, Urban T, Diot P, Racineux JL, and Lemarie E: Gemcitabine aerosol: in vitro antitumor activity and deposition imaging for preclinical safety assessment in baboons. Cancer Chemother Pharmacol. 2006;58:237-244.
26. Tolis C, Peters GJ, Ferreira CG, Pinedo HM, and Giaccone G: Cell cycle disturbances and apoptosis induced by topotecan and gemcitabine on human lung cancer cell lines. Eur J Cancer. 1999;35:796-807.

27. Koshkina NV, Kleinerman ES, Waidrep C, Jia SF, Worth LL, Gilbert BE, and Knight V: 9-Nitrocamptothecin liposome aerosol treatment of melanoma and osteosarcoma lung metastases in mice. Clin Cancer Res. 2000;6:2876-2880.

28. Koshkina NV, and Kleinerman ES: Aerosol gemcitabine inhibits the growth of primary osteosarcoma and osteosarcoma lung metastases. Int J Cancer. 2005;116:458-463.

29. Gagnadoux F, Pape AL, Lemarie E, Lerondel S, Valo I, Leblond V, Racineux JL, and Urban T: Aerosol delivery of chemotherapy in an orthotopic model of lung cancer. Eur Respir J. 2005;26:657-661.

30. McLemore TL, Eggleston JC, Shoemaker RH, Abbott BJ, Bohlman ME, Liu MC, Fine DL, Mayo JG, and Boyd MR: Comparison of intrapulmonary, percutaneous intrathoracic, and subcutaneous models for the propagation of human pulmonary and nonpulmonary cancer cell lines in athymic nude mice. Cancer Res. 1988;48:2880-2886.

31. Gagnadoux F, Le Pape A, Urban T, Montharu J, Vecellio L, Dubus JC, Leblond V, Diot P, Grimbert D, Racineux JL, and Lemarie E: Safety of pulmonary administration of gemcitabine in rats. J Aerosol Med. 2005;18:198-206.

32. Hershey AE, Kurzman ID, Forrest LJ, Bohling CA, Stonerook M, Placke ME, Imondi AR, and Vail DM: Inhalation chemotherapy for macroscopic primary or metastatic lung tumors: proof of principle using dogs with spontaneously occurring tumors as a model. Clin Cancer Res. 1999;5:2653-2659.

33. Tatsumura T, Koyama S, Tsujimoto M, Kitagawa M, and Kagamimori S: Further study of nebulisation chemotherapy, a new chemotherapeutic method in the treatment of lung carcinomas: fundamental and clinical. Br J Cancer. 1993;68:1146-1149.

34. Verschraegen CF, Gilbert BE, Loyer E, Huaringa A, Walsh G, Newman RA, and Knight V: Clinical evaluation of the delivery and safety of aerosolized liposomal 9-nitro-20(s)-camptothecin in patients with advanced pulmonary malignancies. Clin Cancer Res. 2004;10:2319-2326.

35. Otterson GA, Villalona-Calero MA, Sharma S, Kris MG, Imondi A, Gerber M, White DA, Ratain MJ, Schiller JH, Sandler A, Kraut M, Mani S, and Murren JR: Phase I study of inhaled Doxorubicin for patients with metastatic tumors to the lungs. Clin Cancer Res. 2007;13:1246-1252.

36. Wittgen BP, Kunst PW, van der Born $K$, van Wijk AW, Perkins W, Pilkiewicz FG, Perez-Soler R, Nicholson S, Peters GJ, and Postmus PE: Phase I study of aerosolized SLIT cisplatin in the treatment of patients with carcinoma of the lung. Clin Cancer Res. 2007; 13:2414-2421.

37. Knight V, Koshkina NV, Waldrep JC, Giovanella BC, and Gilbert BE: Anticancer effect of 9-nitrocamp- 
tothecin liposome aerosol on human cancer xenografts in nude mice. Cancer Chemother Pharmacol. 1999;44:177-186.

38. Knight V, Kleinerman ES, Waldrep JC, Giovanella BC, Gilbert BE, and Koshkina NV: 9-Nitrocamptothecin liposome aerosol treatment of human cancer subcutaneous xenografts and pulmonary cancer metastases in mice. Ann N Y Acad Sci. 2000;922:151-163.

39. Gagnadoux F, Vecellio L, Prunier C, Hureaux J, Majoral C, Diot P, Boisdron M, Beaulieu JL, Valat C, Halmi JM, Giraudeau B, Grimbert D, Le Pape A, Racineux JL, Urban T, and Lemarié E: A phase I study of aerosolized gemcitabine in non-small-cell lung cancer. J Aerosol Med. 2007;20:176.

40. Vecellio L, Colombier L, Diot P, Le Guellec S, and Chantrel G: In vitro/in vivo performances of the Idehaler holding chamber operating with Aeroneb Pro. J Aerosol Med. 2007;20:189.

41. Koshkina NV, Gilbert BE, Waldrep JC, Seryshev A, and Knight V: Distribution of camptothecin after delivery as a liposome aerosol or following intramuscular injection in mice. Cancer Chemother Pharmacol. 1999;44:187-192.

42. Hitzman CJ, Wattenberg LW, and Wiedmann TS: Pharmacokinetics of 5-fluorouracil in the hamster following inhalation delivery of lipid-coated nanoparticles. J Pharm Sci. 2006;95:1196-1211.

43. Lee KS, Kim Y, Han J, Ko EJ, Park CK, and Primack SL: Bronchioloalveolar carcinoma: clinical, histopathologic, and radiologic findings. Radiographics. 1997;17: 1345-1357.

44. Lubet RA, Zhang Z, Wang Y, and You M: Chemoprevention of lung cancer in transgenic mice. Chest. 2004;125(5 Suppl.):144S-147S.

45. Wattenberg LW, Wiedmann TS, and Estensen RD: Chemoprevention of cancer of the upper respiratory tract of the Syrian golden hamster by aerosol admin- istration of difluoromethylornithine and 5-fluorouracil. Cancer Res. 2004;64:2347-2449.

46. Skubitz KM, and Anderson PM: Inhalational interleukin-2 liposomes for pulmonary metastases: a phase I clinical trial. Anticancer Drugs 2000;11:555-563.

47. Wylam ME, Ten R, Prakash UB, Nadrous HF, Clawson ML, and Anderson PM: Aerosol granulocytemacrophage colony-stimulating factor for pulmonary alveolar proteinosis. Eur Respir J. 2006;27:585-593.

48. Georges RN, Mukhopadhyay T, Zhang Y, Yen N, and Roth JA: Prevention of orthotopic human lung cancer growth by intratracheal instillation of a retroviral antisense K-ras construct. Cancer Res. 1993;53:1743-1746.

49. Fulzele SV, Chatterjee A, Shaik MS, Jackson T, and Singh M: Inhalation delivery and anti-tumor activity of celecoxib in human orthotopic non-small cell lung cancer xenograft model. Pharm Res. 2006;23:20942106.

50. Fulzele SV, Shaik MS, Chatterjee A, and Singh M: Anti-cancer effect of celecoxib and aerosolized docetaxel against human non-small cell lung cancer cell line, A549. J Pharm Pharmacol. 2006;58:327-336.

Received on September 3, 2007 in final form, September 29, 2007

Reviewed by: Tunde Otulana, M.D.

Address reprint requests to: Frédéric Gagnadoux, M.D., Ph.D. Département de Pneumologie $\mathrm{CHU}, 4$ rue Larrey 49033 Angers Cedex, France

E-mail: frgagnadoux@chu-angers.fr 
